\title{
AVALIAÇÃO DE CRESCIMENTO DE MUDAS DE AÇAÍ (Euterpe precatória Mart.) SOB DIFERENTES TIPOS DE SUBSTRATOS
}

\author{
Brás Serifo dos Santos ${ }^{1}$; Sebastião Afonso Pinto ${ }^{2}$; Belizio Correia Tavares $^{3}$ \\ ${ }^{1}$ Graduando, Universidade da Integração Internacional da Lusofonia Afro-Brasileira (Unilab) \\ Aacarape, Ceará, ${ }^{2}$ Graduando, Universidade da Integração Internacional da Lusofonia Afro- \\ Brasileira (Unilab) Redenção, Ceará, ${ }^{3}$ Graduando, Universidade da Integração Internacional da \\ Lusofonia Afro-Brasileira (Unilab) Acarape, Ceará.
}

DOI: 10.47094/ICONNECA.2021/22

\begin{abstract}
RESUMO
Açaizeiro (Euterpe precatória Mart.) ocorre naturalmente na região ocidental da Amazônia brasileira. Para uma boa qualidade de mudas é de grande importância escolha certa de substratos, que vão permitir que ocorra a retenção de água. o presente trabalho objetivou-se avaliar o crescimento de mudas de açaizeiro em diferentes tipos de substratos. $O$ trabalho foi realizado durante 3 meses do ano 2021,no município de Palmácia-CE, na fazenda sitio Rochedo. Adotou-se o delineamento experimental inteiramente casualizado com 4 tratamentos e 5 repetições. Os tratamentos constituírem em substaro $1=50 \%$ de solo $+50 \%$ de cinza; Substrato $2=50 \%$ de solo $+50 \%$ de esterco de bovino; Substrato3 $=33 \%$ de solo $+33 \%$ de esterco de galinha $+33 \%$ de compostagem orgânica e Substrato4= $25 \%$ de solo $+25 \%$ de compostagem orgânica $+25 \%$ de cinza $+25 \%$ de esterco de gado. O uso dos substratos 1 e 2 proporcionou melhores desenvolvimentos no crescimento inicial de mudas produzidas.
\end{abstract}

PALAVRAS-CHAVES: Compostos orgânicos. Maiores desenvolvimentos. Substratos.

ÁREA TEMÁTICA: Outros.

\section{INTRODUÇÃO}

Açaizeiro (Euterpe precatoria Mart.) ocorre naturalmente na região ocidental da Amazônia brasileira e difere da espécie nativa da Amazônia oriental, o açaí-de-touceira (Euterpe oleraceae Mart.) pelo seu estipe solitário e porte geralmente maior. É típico de florestas primárias e ocorre tanto nas áreas de terra-firme como ao longo das margens de rios e igarapés que ficam temporariamente inundadas durante a estação das chuvas (FERREIRA, 2005). Como pode ser verificado que a literatura aponta o Brasil como o maior produtor, consumidor e exportador do fruto dessa espécie, entretanto, far-se necessario produzir mudas de qualidades assim como renovar os plantios de açaizeiros pois essa espécié tem sido alternativa para aumentar renda dos pequenos produtores rurais assim como serve de grande importância para economia do pais. Com isso, cabe lembrar que para que haja uma boa qualidade de produção de mudas é de grande importância a escolha correta de substratos, que vão 
permitir que ocorra o processo de retenção de água, que tenha disponibilidade e suficiente nutrientes para o desenvolvimento das mudas. Mediante o exposto, o presente trabalho objetivou- se avaliar o crescimento de mudas de açaizeiro em diferentes tipos de substratos no município de Palmácia- CE.

\section{METODOLOGIA}

O trabalho foi realizado durante 3 meses ( março, abril e maio) do ano 2021, é uma propriedade rural com sistema de produção orgânica no município de Palmácia (CE), na fazenda sitio Rochedo. A propriedade está localizada em região serrana cearense, microrregião do Maciço de Baturité e Mesorregião do Norte Cearense, localizada geograficamente a $74 \mathrm{~km}$ da capital do estado, sob as coordenadas geográficas: $4^{\circ} 15^{\prime} \mathrm{S}$ e $38^{\circ} 87^{\prime} \mathrm{W}$ e $510 \mathrm{~m}$ de altitude, o clima da região é classificado por Aw, com temperaturas médias variando em torno de 24 a $26^{\circ} \mathrm{C}$. Adotou-se o delineamento experimental inteiramente casualizado DIC com 4 tratamentos e 5 repitições. Os tratamentos constituírem em : Substaro1 $=50 \%$ de solo $+50 \%$ de cinza; Substrato $2=50 \%$ de solo $+50 \%$ de esterco de bovino; Substrato3 $=33 \%$ de solo $+33 \%$ de esterco de galinha $+33 \%$ de compostagem orgânica e Substrato $4=25 \%$ de solo $+25 \%$ de compostagem orgânica $+25 \%$ de cinza $+25 \%$ de esterco de gado. O solo utilizado para prenchiemnto dos substratos, como esterco de bovino, esterco de galinha e cinza ambos foram coletados no mesmo sítio pois o local apresenta uma vasta de diversidade de palntas assim como animais. O plantio das sementes de açaizeiro foi realizado em canteiro constituído de areia, após a emergência das plântulas que se ocorreu entre 30 a 40 dias. Foram escolhidas plântulas com altura média de $3,5 \mathrm{~cm}$, antes da abertura do primeiro par de folhas com dois meses de idade e, se baseou na metodologia utilizada pelo Macêdo, 2014. Em seguida, as plântulas foram transplantadas para sacos pretos de polietileno de 15 x $22 \mathrm{~cm}$ com substratos suficientes. Após a um mês foi feita as medições utilizando uma régua e uma fitamétrica. Avaliou-se: i) altura da planta; ii) largura da folha medida no terço médio dos folíolos centrais; iii) diâmetro de caule, iv) número de folhas por cada palnta. Para avaliação estatística dos efeitos dos tratamentos realizou-se a análise de variância e teste de tukey, ao nível de 5\%.

Figura 1: Medição das mudas de açaizeiro em diferentes tratamentos

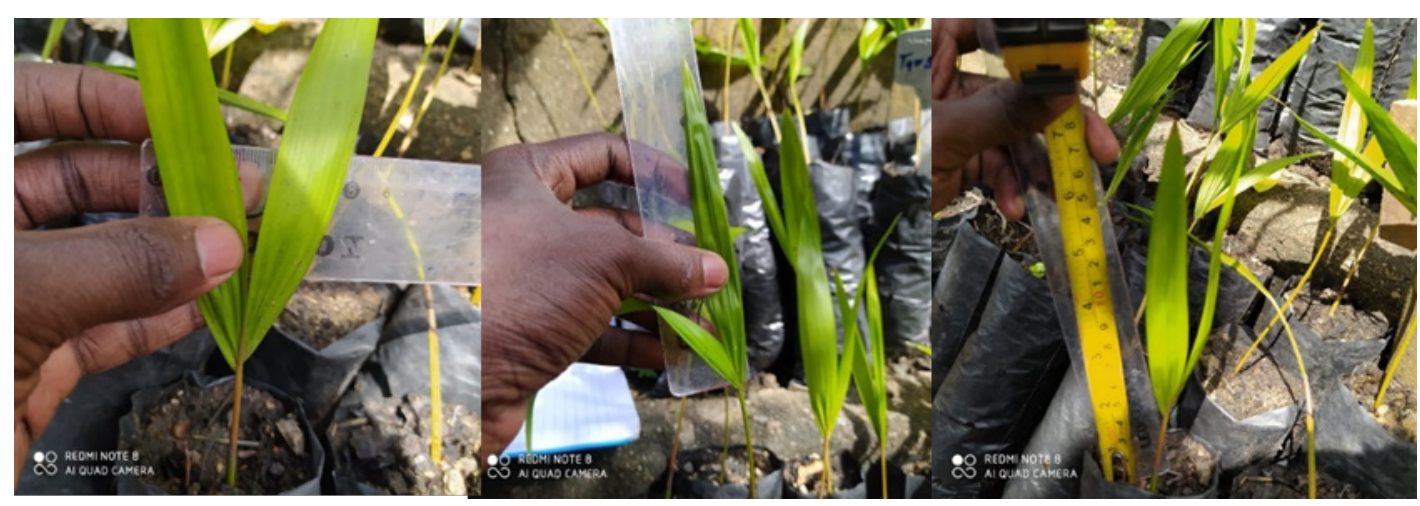

Fonte: Brás Serifo dos Santos 


\section{RESULTADOS E DISCUSSÕES}

Pelos resultados da análise de variância dos dados, verificou-se efeito significativo dos diferentes substratos utilizados para as variáveis respostas altura de plantas em todos tratamentos, no diâmetro do caule em tratamento 4 e número de folhas no tratamento 4 , enquanto que o diâmetro de caule e números de folhas no tratamento 1 não foram significativos. (Tabela 1).

Tabela 1: Resumo da análise de variância dos dados de altura de plantas (AP), diâmetro do caule (DC), número de folhas (NF) e área foliar ( $\mathrm{AF}$ ) de açaí submetidas a diferentes substratos para produção de mudas).

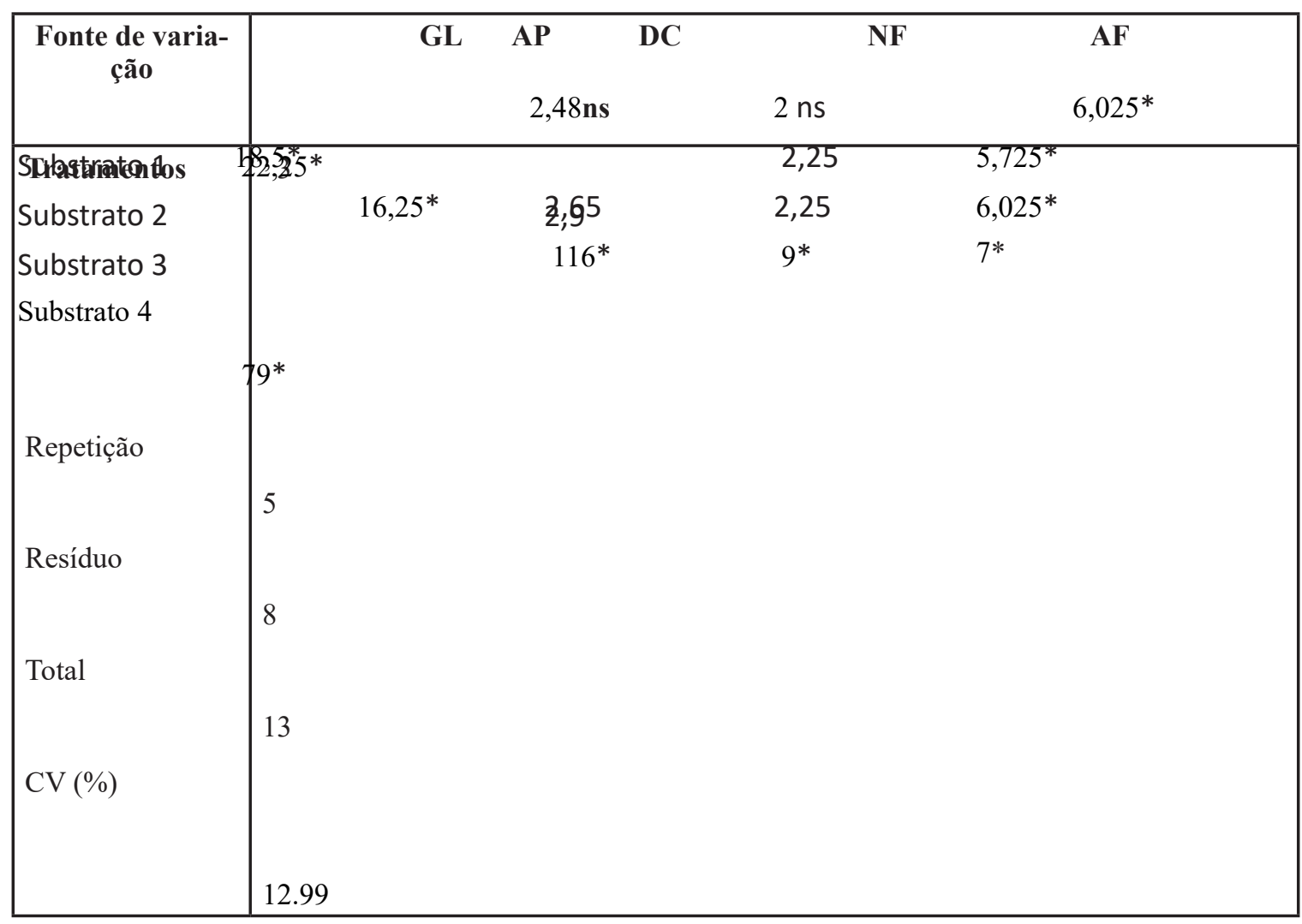

$$
\begin{gathered}
\mathrm{FV}=\text { Fontes de variação } \\
\mathrm{GL}=\text { Graus de liberdade } \\
\mathrm{CV}=\text { Coeficiente de variação } \\
\text { ns }=\text { não significativo } \\
*=\text { Significativo ao nível de } 5 \% \text { de probabilidade. }
\end{gathered}
$$

Um dos elementos que podem ter influenciado no resultado dos substratos 1 e 4 que tiverem maiores respostas provavelmente é a composição de materiais utilizados, respecetivamente $50 \%$ de terra $+50 \%$ de composto orgâncio e $25 \%$ de solo $+25 \%$ de composto orgânico $+25 \%$ de cinza + $25 \%$ de esterco de gado, essas composições têm influênciados varáveis analisadas. 


\section{CONCLUSÃO}

Com objetivo pretendido neste tratabalho, é de perceber que o uso dos substratos 1 com $50 \%$ de terra $+50 \%$ de composto orgâncio e substrato 4 com $25 \%$ de solo $+25 \%$ de composto orgânico $+25 \%$ de cinza $+25 \%$ de esterco de gado proporcionam maiores desenvolvimentos no crescimento inicial de mudas produzidas de açaizeiro.

\section{PRINCIPAIS REFERÊNCIAS}

FERREIRA, E. J. L. Diversidade e importância econômica das palmeiras da Amazônia Brasileira. Anais do $56^{\circ}$ Congresso Nacional de Botânica, Curitiba, Paraná, 2005b.

VIANA, C.M.P.; SOUSA, F.J.; LIMA, K.A.; NASCIMENTO, M.M.S. Perfil Básico Municipal, 2016 - Palmácia. Fortaleza: IPECE, 2016. 17p. Disponível em: <http://www.ipece.ce.gov.br/perfil_ basico_municipal/2016/Palmacia.pdf>. Acesso em: 18 de junho de 2021. 